\title{
Adolescents with cystic fibrosis: psychosocial adjustment
}

\author{
E M BYWATER
}

The Hospital for Sick Children, London

SUMMARY Patients aged between 12 and 16 years with cystic fibrosis were interviewed, as were their parents, to find out if psychosocial problems existed. All 27 of them appeared to be well adjusted and none had special problems at school; they were not socially isolated, and family relationships seemed to be good. Contributing factors were good communication patterns within the family and perhaps denial of the ultimate outcome of the disease, since few patients wished to know more about cystic fibrosis. Comparison with a group of healthy adolescents and their mothers showed that the patients had a tendency (not significant) towards depression. Among the mothers however, the incidence of depression was significantly greater. It was concluded that psychiatric intervention should only be undertaken cautiously with adolescents, but that special help should be given to the mothers as they appeared to carry the main burden of coping with the illness.

An increasing number of patients with cystic fibrosis are now reaching age 16 years $^{1}$ and so are experiencing adolescence. Opinions differ as to whether normal adolescents are especially likely to develop disturbance, but in view of the fact that teenagers do face tasks related to the development of identity, and that this must involve self-evaluation which is more difficult for the physically handicapped child because of his difference from a normal child, it might be reasonable to expect adolescents with cystic fibrosis to show special problems. This suggestion is supported by the results of Burton, ${ }^{2}$ who found that young patients with cystic fibrosis experienced many difficulties. More than half the preschool children in her study showed evidence of disturbed behaviour-for example excessive temper tantrums-and an even greater proportion $(70 \%)$ of schoolchildren exhibited symptoms of social unsettledness - that is they were unforthcoming, under-reactive, timid, and afraid of new situations or tasks.

In the USA Boyle et al ${ }^{3}$ found a higher incidence of emotional disturbance in their group of adolescent and adult patients with cystic fibrosis. Dorner ${ }^{4}$ found adolescents with spina bifida-another chronic physically handicapping condition-to be socially isolated, and often miserable or depressed.

In view of these findings it seemed appropriate to carry out further study of psychosocial factors in adolescents with cystic fibrosis.

\section{Material and methods}

All patients aged between 12 and 16 (mean 14.4) years in September 1977, and attending the Cystic Fibrosis Clinic at this hospital were asked if they would like to take part in the study. There were 30 such patients, but one family failed to reply, one girl was unwilling to co-operate, and one girl agreed to take part but was too unwell to do so, so 27 (14 girls, 13 boys) patients were studied.

The parents and children were interviewed in the hospital on the day of their routine clinic appointment (by EMB) about their attitudes to the illness. Using a semi-structured schedule the patient was first interviewed, and then the parent (or parents) accompanying the child. In 23 cases this was the mother alone, in 2 cases it was the father, and two sets of parents were interviewed jointly.

In addition to the interview the mothers were asked to complete the Malaise Inventory based on the Cornell Medical Index as used in other studies. ${ }^{5}$ Behaviour of the children in school was assessed by the Rutter Child Scale B2 (Teachers), ${ }^{6}$ which was completed by all schools attended by the patients, and the consultant physicians gave a chest $x$-ray score based on the Crispin-Norman scoring system, ${ }^{7}$ which indicated the severity of each child's condition.

\section{Results}

Family structure and social class. All the children 
were living at home except for one boy who attended a weekly boarding school for the physically handicapped.

Twenty-two families had both parents living at home, 4 mothers were divorced and had custody of the children, and one father was divorced with custody of his son.

Fourteen ( $52 \%$ ) families belonged to social classes I and II, $6(22 \%)$ were social class III (non-manual), $4(15 \%)$ were social class III (manual), and only 3 $(11 \%)$ families were in social classes IV and V. The most noticeable feature was that there were so few in classes IV and V. This may be partly explained by the fact that $60 \%$ of the patients had transferred from local hospitals to this Cystic Fibrosis Centre; most of the parents were middle-class and highly articulate, and had asked for the transfer.

Severity of pulmonary involvement. Using the Crispin-Norman scoring system for chest $x$-rays ${ }^{7}$ $9(33 \%)$ patients ( 7 girls and 2 boys) were rated as quite severely ill, with a score of 15 or over; 10 (37\%) patients ( 6 girls and 4 boys) were moderately ill, with a score of $10-15 ; 8(30 \%)$ patients ( 2 girls and 6 boys) were rated as mild, with a score $<10$. Only $6(22 \%)$ patients had been admitted to hospital once, or more than once, during the preceding year.

Attitude of the patient to the hospital and to the illness. Patients attend the Cystic Fibrosis Clinic every 2 months, where they are seen either by a consultant paediatrician or a paediatric registrar. Parents may state whom they wish to see although sometimes choice is dictated by the length of a particular queue. The average consultation lasts for 15 minutes and the parents and patient are generally seen together. The social worker is present at the clinic and referrals are frequently made to her during the clinic. Although a psychiatrist is attached to the team, he is not present at the clinic and any referral to him is seen by appointment later. This means that psychiatric help is requested only rarely. The patients are transferred to an adult hospital when they reach 16 years.

Thirteen ( $48 \%$ ) patients ( 4 girls and 9 boys) were quite happy about transferring to an adult hospital, but $14(52 \%)$ (10 girls and 4 boys) stated they did not wish to transfer, and many of the girls said that they would refuse to do so. None of the boys objected to attending the outpatient clinic but half the girls objected strongly. None of the boys felt that there was any problem over the treatment regimen at home-that is physiotherapy, drugs, and diet-but $3(11 \%)$ of the girls felt so strongly about it that they said they were intending to stop treatment and to leave home when they became 16 years old.
Each patient knew the name of his illness and no one could remember a time when he did not know it. All had a fairly good understanding of cystic fibrosis and realised that there was no cure. Only 9 $(33 \%)$ of them ( 3 girls and 6 boys) wished to find out more about the illness, and only $3(11 \%)$ patients (all boys) had ever talked to the physician alone. The other $24(89 \%)$ patients did not wish to have a talk with the doctor and said 'they preferred not to know more', and only $2(7 \%)$ patients wished to speak to a counsellor-for example a psychiatrist or social worker-about their feelings. When asked what they thought was the worst feature of the illness, only 2 patients referred to the fact that it was incurable, and the other 25 identified physiotherapy, diets, or tablets. Nearly all (26 patients) said that they could talk to their parents about their illness and their worries, although only half the patients had ever done so at any length.

Attitude of the parents to the illness and to the hospital. Each parent said that he was concerned that his child would die and $12(44 \%)$ described themselves as 'worriers'. Only 2 families said that they actively discouraged discussion of cystic fibrosis in the home, but in half the families the patients themselves tried to change the subject whenever cystic fibrosis was mentioned, although the majority of parents resisted this. All the siblings knew about cystic fibrosis, as did all the neighbours and friends of the families. Twenty $(74 \%)$ families supported the Cystic Fibrosis Research Trust and attended meetings regularly, raising money for research, and indeed, many of these families appeared to have a missionary zeal directed towards spreading information about the illness. These 20 families all said that they had learned more about cystic fibrosis from the Cystic Fibrosis Research Trust than from the hospital.

All the parents were satisfied with the medical care that their children received at the clinic and all were able to see the doctor without the child being present. However, only $5(15 \%)$ parents felt that they were positively encouraged to discuss their difficulties, while $20(77 \%)$ said that if they initiated a discussion the doctor was prepared to join in. Two $(7 \%)$ parents felt that they were discouraged from discussing problems.

The person, other than the spouse, to whom each parent found it most helpful to talk when concerned about his child is shown in Table 1.

Parents seemed to receive little support from agencies outside the hospital apart from the Cystic Fibrosis Research Trust, although each parent had consulted the head teacher of his child's school during the preceding year. None of the parents had been in contact with a local authority social services 
Table 1 Person found most helpful by parent when concerned

\begin{tabular}{|c|c|c|c|c|}
\hline No concern & $\begin{array}{l}\text { General } \\
\text { practitioner }\end{array}$ & $\begin{array}{l}\text { Hospital } \\
\text { doctor }\end{array}$ & $\begin{array}{l}\text { Social } \\
\text { worker }\end{array}$ & Other \\
\hline No (\%) & No $(\%)$ & No (\%) & No $(\%)$ & No $(\%)$ \\
\hline 3 (11) & 2 (7) & $18(67)$ & 2 (7) & 2 (7) \\
\hline
\end{tabular}

department, although $12(44 \%)$ parents were currently seeing the medical social worker at the hospital. None of the families had seen a psychologist or psychiatrist during the previous year, although 3 mothers said they thought that this might have been helpful.

Behaviour at school. Using the cut-off point of nine points or more on the Rutter Child Scale B2 (Teachers), ${ }^{6}$ only $2(7 \%$ ) patients ( 1 boy and 1 girl) had behaviour problems at school, compared with $6.6 \%$ of normal 14 -year-old children. ${ }^{8}$

The girl attended a special school and came from a disturbed family background and the boy was at a comprehensive school and it seemed likely that his difficulties arose from the fact that he had an IQ of 150 and the school was unable to stretch him academically. Twenty-three $(75 \%)$ parents were happy with their children's progress at school, but $4(15 \%)$ parents felt that their children had general learning problems. These 4 children ( 2 boys and 2 girls) came from families in which there was current marital conflict or in which a previous marriage had ended in divorce. Most parents felt that the illness did not interfere with school work and all the patients felt that doing well at school was extremely important, so that they were prepared to do extra work to keep up with their class.

The boys were much more enthusiastic about physical education and games than the girls, and of the 3 boys who did not participate, 2 would have liked to have done but were too ill, and 1 boy said that he was not interested. The 5 girls who participated with difficulty disliked games and tried to avoid taking part (Table 2).

Social relationships. The teenagers in this study did not appear to be socially isolated and this was true

Table 2 Participation in games and physical education

\begin{tabular}{|c|c|c|c|c|c|c|}
\hline & \multicolumn{4}{|c|}{ Participates } & \multirow{2}{*}{\multicolumn{2}{|c|}{$\begin{array}{l}\text { Does not } \\
\text { participate }\end{array}$}} \\
\hline & \multicolumn{2}{|c|}{ Without difficulty } & \multicolumn{2}{|c|}{ With difficulty } & & \\
\hline & No & $(\%)$ & No & $(\%)$ & No & $(\%)$ \\
\hline Girls & 6 & (46) & 5 & (38) & 3 & (16) \\
\hline
\end{tabular}

even for patients who were graded as quite severely ill. Patients were judged to be isolated if they had had no peer contact during the preceding month. Twenty-one ( $78 \%$ ) patients had a special friend of the same sex, while $6(22 \%)$ did not. It should be noted that of the 9 quite seriously ill patients, 8 were able to visit the homes of friends, 8 had friends to their homes, and 3 had been able to go out on trips with friends during the previous month. Twenty-five patients said that they were not teased or bullied either in or out of school, but 1 girl and 1 boy felt that they were teased somewhat more than others. Only 2 patients had a special friend of the opposite sex. The parents all felt able to lead an unrestricted social life and all said that they could go out together whenever they wished. However, those with quite seriously ill children ( 9 families) never went out without the patient, although all had family outings -at least 2 during the previous month.

Depression. Many of the parents found it difficult to acknowledge that their children experienced depression, a fact also reported by Dorner ${ }^{9}$ in his interviews with parents of adolescents with spina bifida. However, $63 \%$ of the patients themselves admitted to feelings of misery during the preceding year. Girls appeared more likely to have felt miserable than the boys (Table 3). These results are similar to those obtained for a group of normal 14-year-old children $^{5}$ in which nearly $45 \%$ of the children had experienced feelings of misery $(42 \%$ of the boys and $48 \%$ of the girls). Four girls in the present study had at some time felt that life was hopeless and not worth living; no boy had felt like that.

The results showed the patients more seriously affected with cystic fibrosis contained a somewhat higher proportion $(75 \%)$ of those feeling very miserable, than the proportion $(47 \%)$ of those less

Table 3 Sex of patient and feelings of misery

\begin{tabular}{|c|c|c|c|c|c|c|}
\hline & \multicolumn{6}{|c|}{ Miserable } \\
\hline & \multicolumn{2}{|c|}{ Frequently } & \multicolumn{2}{|c|}{ Sometimes } & \multicolumn{2}{|c|}{ Never } \\
\hline & No & $(\%)$ & No & $(\%)$ & No & $(\%)$ \\
\hline $\begin{array}{l}\text { Boys } \\
\text { Girls }\end{array}$ & $\begin{array}{l}3 \\
8\end{array}$ & $\begin{array}{l}(23) \\
(57)\end{array}$ & $\begin{array}{l}3 \\
3\end{array}$ & $\begin{array}{l}(23) \\
(21)\end{array}$ & $\begin{array}{l}7 \\
3\end{array}$ & $\begin{array}{l}(54) \\
(21)\end{array}$ \\
\hline
\end{tabular}

Table 4 Relationship of misery to the severity of the illness

\begin{tabular}{llllll}
\hline & \multicolumn{2}{l}{ Miserable } & & \multicolumn{2}{c}{ Not miserable } \\
\cline { 2 - 3 } \cline { 5 - 6 } \cline { 5 - 6 } & No & $(\%)$ & & No & $(\%)$ \\
\hline Severely ill & 9 & $(33)$ & 3 & $(11)$ \\
Mildly ill & 7 & $(27)$ & 8 & $(29)$ \\
\hline
\end{tabular}


seriously affected. However the difference was not statistically significant $\left(P>0.05 \chi^{2}\right.$ test).

Depression-that is loss of energy, tearfulness, inability to sleep-was found to be pronounced in $12(44 \%)$ of the mothers in this study and was significantly higher $(\mathrm{P}<0.001)$ than the $14 \%$ of the mothers found depressed in a study of normal 14-year-old children. ${ }^{5}$ The mother's depression seemed to be related to the severity of the child's illness, as $8(67 \%)$ of the 12 mothers who were depressed had quite seriously ill children.

On the Malaise Inventory, 8 (31\%) mothers answered 'yes' to at least 7 questions indicating malaise, compared with $11 \%$ of mothers in Rutter's group $(\mathrm{P}<0.01) .^{5}$ This proportion of depressed mothers is similar to that of Dorner ${ }^{9}$ who found that $32 \%$ of mothers of children with spina bifida suffered from malaise.

None of the wives felt that her husband was depressed, and none of the few men who were interviewed admitted to depression. All the mothers felt that being in full-time employment removed the men from direct exposure to the illness. In fact many of the mothers also worked outside the home; one mother was a full-time student, and $18(67 \%)$ of the mothers were in employment-one full-time and the others part-time. All of these 18 mothers frequently felt miserable. Most of the mothers felt that they worked primarily to escape from the illness and to forget about it for part of each day. Six mothers of the 9 quite severely ill patients were able to work part-time. There had been marital breakdowns in $5(18 \%)$ cases which compares with $12 \%$ of the general population after a similar average number of years of marriage. ${ }^{10}$ This difference was not statistically significant.

Four other parents said that they were unhappily married and that the marriage would have ended had it not been for their ill children. Of the 5 divorced parents 4 said that the marriage had broken down because of the genetic basis of the illness, and 3 of the 4 parents who were unhappily married also blamed the genetics of the illness.

Family relationships. Most of the teenagers felt that they had good family relationships and could talk to their parents, and that the family did things together. Twenty-two $(81 \%)$ patients said that they had no difficulties with their mothers, $20(74 \%)$ patients had no difficulties with their fathers, and $19(70 \%)$ patients had no difficulties with siblings.

Families in which a sibling had died from cystic fibrosis. It might have been expected that the $6(22 \%)$ patients and families that had already suffered the loss of a child through cystic fibrosis would be particularly vulnerable to stress. However not one of these patients was experiencing any difficulties at school, none was isolated, and the family relationship in five of the families was excellent. All the patients knew about the dead siblings as all the parents had discussed the subject with the affected child, although most parents had stressed that the child who had died had been much more severely ill.

Four of these 6 mothers were depressed and one of the marriages was unhappy, being one of those only remaining intact because of the ill child.

\section{Discussion}

This study was undertaken in order to find out how families with an adolescent cystic fibrosis patient coped with the illness and to identify the problems, both social and psychological, which the patients themselves experienced.

Studies in the USA ${ }^{311} 12$ suggest that there is a higher incidence of emotional disturbance-that is excessive anxiety, unexpressed anger, poor self image, and inadequate peer relationships-among patients with cystic fibrosis (not only adolescent) than in the general population. However, although the present study shows that there is a tendency towards more depression and misery among adolescents with this condition than is found in a normal group, the difference was not pronounced-that is $63 \%$ compared with $45 \%$, and not statistically significant. Girls did seem to show misery and sadness more often than boys, but they also tended to be more seriously ill. The girls however, did seem more likely to react negatively to the illness than boys. For example, the girls were more likely to object to the transfer to an adult hospital and to attending the clinic.

School did not present any real difficulties for the patients, although the girls performed less well than the boys at physical education and at games. Indeed most boys participated with such enthusiasm that it seemed to give them an extra interest in life, and 2 of the 3 boys who could not take part seldom missed a football match when their local team was playing. Contrary to other studies, the patients in the present study did not appear to be socially isolated, including even those who were quite seriously ill. However, it must also be added that the majority of these patients did not put themselves into a position where they might suffer rejection or feel socially isolated as only 2 teenagers went to discothèques or dances. They also appeared to be immature and only 2 had friends of the opposite sex.

Family relationships appeared to be good with the 
affected teenagers having if anything fewer arguments with their parents than normal children. ${ }^{5}$ Conceivably this might indicate inability to show independence but they also had fewer difficulties with siblings.

Therefore most patients seemed to cope with the illness and with their daily lives. Why should this be so in view of the ultimate outcome of the disease? Most researchers into this aspect of cystic fibrosis have found, to quote Boyle et al. ${ }^{3}$ 'that good communication in the home . . . leads to more adaptive behaviour on the part of the young adult', a point also made by Turk. ${ }^{13}$ As stated earlier most families did not hide the illness and the fact that $74 \%$ of the parents were enthusiastic members of local groups organised by the Cystic Fibrosis Research Trust seems to indicate a willingness to talk about cystic fibrosis. This finding can be contrasted with that of Allan et al. ${ }^{14}$ who found that two-thirds of their Australian group were unwilling to join any cystic fibrosis association. Indeed Tropauer et al. ${ }^{11}$ made the point that the child's method of coping with cystic fibrosis exactly reflected that of his parents, and in that study most parents dealt with the illness openly.

The patients may also have coped with the illness by denying the ultimate outcome of the disease. Bronheim ${ }^{15}$ states that 'in order to function the patient must deny death but not the disease', while Boyle et al. ${ }^{3}$ found that the main mechanisms used by all their patients to deal with death were denial and avoidance, even when they were very ill. It might therefore be assumed that some degree of denial was present in this group of patients. Denial may be assumed to have been an important defence mechanism for the 3 girls who were planning to stop treatment and to leave home. Indeed one girl could not bear to see her younger brother, who also had cystic fibrosis, take his drugs or have his physiotherapy, as it reminded her that she had the illness too, and it made her 'unbearably depressed', to such a degree that she wished to leave home. However as most patients did not seem to have evidence of underlying anxiety it cannot be firmly stated that 'denial' was an important part of their coping mechanisms. No child was acutely ill at the time of interview and this may have affected the responses. However, none of the school reports indicated undue anxiety in the child, although 7 patients did have difficulty concentrating, and 10 had nervous habitsfor example, stammering and nail-biting.

This study, in common with others-for example, Allan et al. ${ }^{14}$-does appear to indicate that the major part of the burden of coping with the child and the illness is carried by the mother, and at some cost to her emotional well-being, as the mothers' rate of depression was higher than in normal mothers ${ }^{5}$ and in mothers of adolescent patients with spina bifida. ${ }^{9}$ Mothers of more severely ill patients were more likely to be depressed. It was striking that none of the fathers seemed to be depressed and this may indicate that their wives bore the brunt of the illness, or alternatively to quote Dorner, ${ }^{9}$ that the mothers interviewed were 'unable to recognise their husbands' depression'. Many ( $70 \%)$ of these mothers were able to spend time out of the home either at work or at university, and all of them felt that this was necessary in order to preserve their sanity. Yet those working were as depressed as those not working. The mothers received virtually no support from community agencies, their major sources of help being the hospital and the Cystic Fibrosis Research Trust. However, all the mothers said that they preferred to relate mainly to the staff of the hospital and in particular to their consultant physician. This implies that medical teams should respond by being more positive in encouraging parents to discuss their difficulties. Only $15 \%$ of mothers felt that they received positive encouragement from the hospital doctor to talk about problems. Paediatricians should also be alert to the possibility of referral to the social worker or psychiatrist. Several mothers did not realise that social work help was available. More information about sources of help should be available to parents at clinics. It might also help the mothers if the patients could be encouraged to take more responsibility for their illness by having regular talks, alone, with the physician in a way that would not threaten their defences or cause anxiety. It would certainly be beneficial if the fathers could be encouraged to share in the care of their ill children, as suggested by Allan et al., ${ }^{14}$ and this attitude could be initiated at diagnosis.

This study seems to indicate that most of the patients did not appear maladjusted or suffering from emotional disorder. It is arguable whether attempts to intervene with those not showing symptoms might lead to the development of less satisfactory defence mechanisms or to a better quality of life. Certainly there is a need for caution in child psychiatric referral unless behavioural symptoms are overt and accepted as present to a troubling degree by the child and his family.

The study also showed that attention should be paid to helping mothers, many of whom are depressed and most of whom receive little support from either the hospital or the community. The majority of these mothers said that they would welcome help if it were offered. 
I thank Dr A P Norman, Professor P Graham, and Mr S Dorner for assistance, and the Cystic Fibrosis Research Trust for providing financial support.

\section{References}

1 Robinson M J, Norman A P. Life tables for cystic fibrosis. Arch Dis Child 1975; 50: 962-5.

2 Burton L. Family life of sick children. London: Routledge \& Kegan Paul, 1975: 157-88.

3 Boyle I R, di Sant'Agnese P A, Sack S, Millican F, Kulczycki L L. Emotional adjustment of adolescents and young adults with cystic fibrosis. $J$ Pediatr 1976; 88: 318-26.

4 Dorner S. Adolescents with spina bifida. How they see their situation. Arch Dis Child 1976; 51 : 439-44.

5 Rutter M, Graham P, Chadwick O F D, Yule W. Adolescent turmoil; fact or fiction? J Child Psychol Psychiatry 1976; 17: 35-6.

6 Rutter M. A children's behaviour questionnaire for completion by teachers; preliminary findings. $J$ Child Psychol Psychiatry 1967; 8: 1-11.

7 Crispin A, Norman A. The systematic evaluation of the chest radiograph in cystic fibrosis. Pediatr Radiol 1974; 2: 101-6.

8 Graham P, Rutter M. Psychiatric disorder in the young adolescent. A follow-up study. Proc R Soc Med 1973; 66: 1226-9.
9 Dorner S. The relationship of physical handicap to stress in families with an adolescent with spina bifida. Dev Med Child Neurol 1975; 17: 765-76.

10 Department of Health and Social Security. Marriage and divorce statistics. Series FM2. No 4. London: HMSO, 1977: 79.

11 Tropauer A, Franz M N, Dilgard V W. Psychological aspects of the care of children with cystic fibrosis. Am J Dis Child 1970; 119: 424-32.

12 McCollum A T, Gibson L E. Family adaptation to the child with cystic fibrosis. J Pediatr 1970; 77: 571-8.

13 Turk J. Impact of cystic fibrosis on family functioning. Pediatrics 1964; 34: 67-71.

14 Allan J L, Townley R R W, Phelan P D. Family response to cystic fibrosis. Aust Paediatr J 1974; 10: 136-46.

15 Bronheim S P. Pulmonary disorders, asthma, and cystic fibrosis. In: Magrab P R, ed. Psychological management of pediatric problems. Baltimore: University Park Press, 1978: chapter 11.

Correspondence to Mrs E M Bywater, Social Services Department, The Hospital for Sick Children, Great Ormond Street, London WC1N 3JH.

Received 19 May 1980 